\title{
THE HISTORY OF ASTIN
}

INVITED LECTURE AT THE 50 YEARS ANNIVERSARY OF ASTIN

BY

HANS BÜHLMANN

\section{Prologue}

"War is the father of all things". This sentence of Heraklit (between 540 and $535 \mathrm{BC}$ ) has a lot of truth in general. I am quoting it in connection with World War II (1939-1945) and inventions originating in this period.

The best known examples of inventions (or first practical use of such inventions) are

- Nuclear Fission leading to the construction of the atomic bomb and nuclear reactors,

- The Programmable Electronic Computer. Best known is the machine of John von Neumann at Los Alamos: Mathematical Analyser Numerical Integrator and Computer (MANIAC),

- RADAR to guide the airplanes particularly at night and in bad weather conditions,

- Penicillin to fight bacteriological diseases.

Some of these inventions relied on original discoveries already made before the war, but during the war they were for the first time used on a large scale.

Also in applied mathematics important topics have originated in World War II:

- Game Theory (Neumann-Morgenstern 1944). The application of Two Person Zero Sum Games for military purposes is straight forward,

- Linear Programming (George Dantzig 1947, Kantorovich 1939). The idea of optimizing logistics has taken a major role in military supply,

- Sequential Statistical Testing (Abraham Wald 1944). The considerable savings in sample size has had an enormous effect on military production.

Generally speaking, in World War II the area of probability theory and statistics assumed an important role in applied mathematics.

Many mathematicians and actuaries did serve their countries in special units where mathematics was the core of their activity. The best known examples were 
- CRyptology Units where you had to crack the enemy's code of telegraphic transmission,

- Operations Research Units where you had to solve strategic or logistic problems formalizing decision making through mathematical modeling.

It seems natural that after the war many of the new topics in applied mathematics were continued and further developed: Operations Research was applied to economy instead of warfare, Linear programming was applied to agriculture instead of military supply. Quality Control lended itself easily to general manufacturing. Decision Theory became a management tool, etc. etc.

What about a new orientation in the Insurance Sector after World War II? The big step for a new paradigm had been made quite early in Scandinavia. Filip Lundberg (Lundberg 1909) had proposed to understand the insurance activity as a stochastic process. The idea was the more revolutionary as in 1909 the mathematics of stochastic processes was not available. Professor Cramér filled this gap (Cramér 1930), but collective risk theory, as it came to be called, was such a huge change of paradigm that only a few people grasped its importance. Only after World War II some courses on the subject started to pop up.

But the practical actuaries played an important role as well. Those who returned from military service in specialized units were eager to make use of their new skills developed while serving their country. They started to work also outside life insurance and gradually extended their range of activity to

i) application of mathematical statistics in all areas of insurance,

ii) stochastic modeling of the insurance process,

iii) decision theoretic analysis of management activities.

In activity i) only the European side entered new fields whereas the North American casualty actuaries (CAS founded in 1914) had already developed considerable expertise in Non-Life statistics, e.g. in the field of credibility (Whitney 1918). On the other hand ii) and iii) were new areas everywhere.

Little groups - enthusiasts for a new dimension of the actuary - were informally appearing in many countries.

The biggest group grew in Scandinavia around Cramér (Segerdahl, Johansen, Benckert, Philipson, Sternberg, Benktander, Pentikäinen, Mattson, Ove Lundberg, Sparre Anderson, Wilhelmson); smaller groups in France (Dubourdieu, Depoid) Italy (Cantelli, de Finetti, G. Ottaviani) as well as important singletons: Robert Beard (Great Britain) Hans Ammeter (Switzerland), Edouard Franckx (Belgium).

In North America the situation was different. The Casualty Actuarial society did already exist and had gained an important status in the industry for promoting scientific approaches to insurance rating and reserving. But also inside the Casualty Actuarial Society remarkable colleagues were striving for new horizons (Arthur Bailey, Perryman, Longley-Cook). 


\section{A First ATtempt}

In November 1953 a circular letter was sent to a selected circle of interested persons informing them that a new actuarial Association called ASTIN was going to be created to promote the scientific development and the theory of non-life insurance. A preparatory committee Ammeter, de Finetti, Franckx, de Jong, Monic Sousselier, Vajda had been formed. It was hoped that on the occasion of the forthcoming International Congress of Actuaries in Madrid (June 1954) the founding meeting could proceed with the actual formation. The meeting was scheduled with a lecture to follow by Ingvar Sternberg on "The fire frequency in relation to working hours in industry" and a lecture by Hans Ammeter on Collective Risk Theory.

From the documents I have seen it is clear that the foundation did not take place as planned. The Comité Permanent (predecessor of IAA) had intervened by insisting that ASTIN should not be an independent Association but a Subsection of the International Congresses and the Comité Permanent proposed to change its statutes in this respect. The formation of ASTIN was hence delayed to be effected at the International Congress in New York 3 years later.

Following this interruption considerable discussions took place among the founders of ASTIN. ASTIN wanted above all complete freedom to publish a bulletin and to hold its own scientific meetings (colloquia). For this freedom complete financial independence was needed. It seems that the Comité Permanent was willing to agree on that. On other points, in particular the definition of membership, the discussion was sometimes quite emotional.

28th July 1954 "If the international committee does not intend to give ASTIN its whole-hearted support we should instead start something independently supported by those individuals and national associations who would like to see results (Johansen to Monic)"

23 August 1954 Franckx suggests as an alternative to have the "patronage" of the Universities (Belgian, Scandinavian) instead of the Comité Permanent.

Nevertheless it seems somehow that agreement could finally be reached. Both sides agreed on an official session treating an ASTIN subject during the International Congress in New York. During this Congress the inaugural meeting of ASTIN would also be held.

\section{The Successful Event}

On October 16, 1957 this Inaugural Meeting of ASTIN took place at 2:30 pm in the Hotel Commodore in New York. 46 members were present. I would guess that Paul Johansen and Gunnar Benktander are the only ones of those 
46 still alive. They both would have liked to be with us today. Paul Embrechts will transmit to you Gunnar's personal message of congratulations at the end of my lecture and Mette Havning will do the same for Paul Johansen.

The only two items of formal business were

- agreement on the rules for the section ASTIN of the Permanent Committee

- election of the first committee of ASTIN

Sir George Maddex representing the Permanent Committee

Robert Beard

Edouard Franckx

Paul Johansen

Boleslav Monic

Francis Perryman

Carl Philipson

In the first committee meeting right after inauguration the officers were chosen as

$\begin{array}{ll}\text { Chairman } & \text { Paul Johansen } \\ \text { Secretary } & \text { Robert Beard } \\ \text { Editor } & \text { Edouard Franckx } \\ \text { Treasurer } & \text { Boleslav Monic }\end{array}$

Franckx did not act as first editor. This duty was performed by the secretary during the first year.

If you look up Volume 1 of the ASTIN Bulletin you will find "Surveys on Actuarial Activity in General Insurance in different parts of the world at the time of the legal ASTIN foundation". They clearly document that ASTIN had a solid platform of theoretical knowledge and practical experience on which it now could continue to flourish.

Two days after its official birth ASTIN presented itself to the large community of actuaries. The session under Subject IVA was entitled "Analytical Expressions of Risks Involved in General Insurance". 16 papers were discussed in this session

$\begin{array}{ll}7 & \text { from Sweden } \\ 2 & \text { from Denmark } \\ 2 & \text { from Italy } \\ 1 \text { each } & \text { from England, the Netherlands, Belgium, France and Switzerland. }\end{array}$

The statistical figures reflect quite well the early influences on ASTIN activities, Scandinavia being largely in the lead. It is also obvious that the Anglosaxon colleagues were rather on the sceptical side when ASTIN took off. This is best documented by the introductory report to the session IV-A by C.A. Spoerl. Like all other rapporteurs of the Congress he must have been chosen by the New York organizers. I quote from the printed Congress Volume IV. 
"Before turning to the papers, it might not be amiss to comment on the different position occupied by the theory of risk in Great Britain and North America as compared with continental Europe. The subject does not appear in the course of study of the Society of Actuaries or in the syllabus of the Institute or Faculty and is not treated in the basic textbooks published by these societies. In Europe it has occupied a rather distinguished place ever since its initial development by the Scandinavians and its further development has engaged the attention of many prominent actuaries. Perhaps the feeling here is that the theory of risk is a highly technical, almost an academic, subject most suitable for advanced study at the university. In the English-speaking countries, where only a small part of the actuarial training is given in the colleges and universities, I think that the general attitude is that it is too recherché to be of interest to the general run of actuaries."

Well, this was a good shot to start the discussion. The printed record shows that at least two persons reacted. The first was Professor Cramér who in an elegant argument stressed that "the theory of stochastic processes can be said to be sufficiently wide to provide a mathematical frame for practically all the approaches that seem likely to be put forward with the theory of risk". The second was Teivo Pentikäinen who explained that Finnish supervision was using mathematical risk theory. He advocated popularizing risk theory and to compose a concise textbook of which the Finns already had a preliminary draft. Out of this grew ultimately the text by Beard/Pesonen/Pentikäinen (Beard et al. 1969).

\section{EARLY IDEAS}

Until now I have tried to sketch the origins of ASTIN in a chronological fashion. I now would like to speak about the ideas ASTIN wanted to propagate and how these ideas have further developed.

A good way to start is Professor Cramér's 1955 "Survey on Collective Risk Theory from the Point of View of the Theory of Stochastic Processes" (Cramér 1955). According to Cramér the two fundamental problems in risk theory are

\section{The distribution of total claims cost at a fixed time $t$}

Problem 1: $R(t)=\sum_{j=1}^{N(t)} Y_{j}$

$$
\begin{aligned}
N(t) & \sim \text { number of claims in }(0, t] \\
Y_{j} & \sim \text { amount of claim number } j
\end{aligned}
$$

independence assumption for $\left\{N(t), Y_{1}, Y_{2}, \cdots\right\}$ 
FIND:

$$
\begin{aligned}
G_{t}(x)=P[R(t) \leq x] & =\sum_{n=0}^{\infty} p_{n}(t) F^{* n}(x) \\
& =\sum_{n=0}^{\infty} e^{-\lambda t} \frac{(\lambda t)^{n}}{n !} F^{* n}(x)
\end{aligned}
$$

This problem still probably is the most important task of the Non-life actuary. It has almost become routine:

Find in a first step

$$
\begin{aligned}
& F(x) \sim \text { distribution of single claim amount } \\
& p_{n}(t) \sim \text { distribution of number of claims }
\end{aligned}
$$

Then calculate $G_{t}(x)=\sum_{n=0}^{\infty} p_{n}(t) F^{* n}(x) \sim$ distribution of total claims.

We must remember that originally - given $F(x)$ and $p_{n}(t)$ - obtaining $G_{t}(x)$ was a formidable task. It was Harry Panjer (Panjer 1980) who (25 years after Cramér's survey) showed how the problem could be solved by recursion. Harry Panjer triggered a whole new area, which I would call risk theory numerics. In this area actuaries began also to learn from numerical analysts that another way to solve the problem was by FFT (Fast Fourier Transform), [see e.g. (Henrici 1970)].

\section{The stochastic process of the surplus}

Problem 2: Given the process of the surplus

$$
U(t)=\left\{u_{0}+c t-R(t) ; t \geq 0\right\} \sim \text { surplus process }
$$

FIND: The probability of ruin

$$
\begin{aligned}
\Psi\left(u_{0}\right) & =P[U(t)<0 \quad \text { for one } t \in(0, \infty)] \\
& =P[\tau<\infty] \quad \tau \sim \text { time of ruin }
\end{aligned}
$$

Problem 2 is aimed at answering the question: When is the risk process of an insurance company acceptable, when not. The founding fathers of risk theory were taking the point of view of the engineer: The insurance process is acceptable, if its probability of failure is below a given benchmark.

It is remarkable that at the beginning there was little discussion on whether the engineers' attitude was the right one for controlling the risk process of an insurance company. Indeed many mathematicians were intrigued by the mathematical challenge to calculate ruin probabilities, whereas many practical 


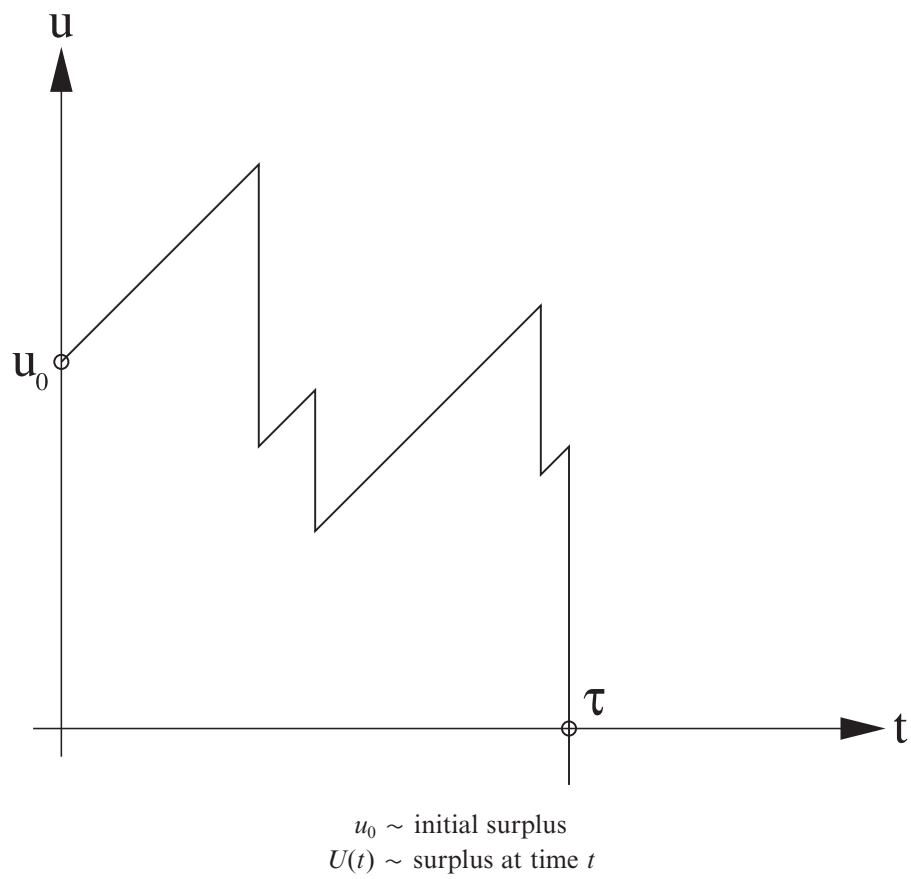

actuaries did not realize what was going on. The exception to the rule was Bruno de Finetti. But his point of view expressed at the International Congress of New York had no echo.

\section{REFINEMENTS}

\section{Fluctuating basic probabilities}

The first refinement of Cramér's program addresses what we would call today parameter risk. Take the aggregate claims distribution in its standard form

$$
G_{t}(x)=\sum_{n=0}^{\infty} e^{-\lambda t} \frac{(\lambda t)^{n}}{n !} F^{* n}(x)
$$

which is driven by the "parameters" $\lambda$ for frequency and $F(x)$ for severity, both remaining the same over the whole time range of the process.

Variability of the parameters should be modeled by making them random. This attitude was taken by Ove Lundberg (Lundberg 1948), son of Filip Lundberg, and independently Hans Ammeter (Ammeter 1948). In their model the parameter $\lambda$ is drawn at random either at the beginning of the process or iteratively during the whole lifetime of the process. The success of their approach 
was remarkable: They could much more convincingly adjust the risk model to real data in an insurance company. The approach came to be propagated under the name "Fluctuating Basic Probabilities".

\section{Inclusion of Interest and Experience Rating}

It is convenient to write the surplus process in differential form

$$
\begin{gathered}
U_{0}=u_{0} \\
d U(t)=c d t-d R(t)
\end{gathered}
$$

If interest at instantaneous rate $\delta$ is included we obtain

$$
d U(t)=c d t+U(t) \delta d t-d R(t) .
$$

Now we have great freedom to modify the risk process

\begin{tabular}{ccll}
\hline \hline $\begin{array}{c}\text { claims process } \\
R(t)\end{array}$ & $\begin{array}{c}\text { premium } \\
c\end{array}$ & \multicolumn{1}{c}{$\begin{array}{c}\text { interest } \\
\delta\end{array}$} & \\
\hline CP & fixed & 0 & (Lundberg 1909)/(Cramér 1930) \\
CP & fixed & fixed $\neq 0$ & (Segerdahl 1959)/(Gerber 1980) \\
WCP & Bayes & 0 & (Dubey 1974) \\
WCP & Bayes & fixed $\neq 0$ & not solved \\
CP & fixed & stochastic & not solved \\
WCP & Bayes & stochastic & not solved \\
\hline \hline
\end{tabular}

$\mathrm{CP} \sim$ Compound Poisson Process

WCP $\sim$ Weighted Compound Poisson Process

The table shows that analytical mathematics reaches its limits soon. Of course in modern times there is no reason to give up. One can always proceed by computer simulation. This is the point of view taken in the monograph by Daykin/ Pentikäinen/Pesonen (Daykin et al. 1994). The simulation studies are called dynamic financial analysis (DFA) and the method can be applied to almost any generalization of the risk process. This is both the strength and the weakness of DFA. The critical question is: Where should generalization stop?

\section{Martingales}

It is Hans Gerber's merit (Gerber 1973) to have introduced martingales in risk theory. The idea is old, it goes back to de Moivre. Look again at the surplus process

$$
\left\{U(t)=u_{0}+c t-R(t) ; t \geq 0\right\}
$$


If $R(t)$ is homogeneous compound Poisson one can easily find an associated martingale

$$
M(t)=e^{-k U(t)} .
$$

For this purpose one has to choose the right value for $k$, which should be the solution of

$$
\lambda+c k=\lambda E\left[e^{k Y}\right] .
$$

Applying the theory of stopping times the probability of ruin calculation - for which the early pioneers needed high power complex analysis - becomes very easy.

The following remark is however more important. The transformation of the risk process into a martingale builds a direct bridge to mathematical finance.

\section{Ideas from other sources}

In the fifty years of its existence ASTIN has evolved enormously and has extended its focus far beyond the basic ideas of the founding fathers. I cannot give a complete account here and I apologize to those colleagues whose ideas I may have missed in the following list
Credibility Theory
Claims Reserving
Tariff Factorization
Premium Calculation Principles
Extreme Values - Catastrophes
Multidimensional Techniques - Copula
Reinsurance
Solvency Margins
Capital Allocation

Particularly the first three topics have strong roots in the United States and have always been on the agenda of the Casualty Actuarial Society.

In the final part I want to talk about influences from economics.

\section{Economics}

I have mentioned earlier that the founding fathers looked at the risk process of an insurance company with the attitude of an engineer: "Control the probability of failure".

It is remarkable that already at the New York Congress 1957 Professor Bruno de Finetti (de Finetti 1957) proposed a different goal: "Maximize the value of the firm". And he gave also a mathematical method for achieving this 
goal (at least in a toy model version). In the printed discussions of the New York Congress you can read that de Finetti's proposal was hardly noticed. De Finetti says that it may be due to the fact that his article was written in Italian. I think that the proposal was such an enormous shift in paradigm that it fell into the void. However, already in the first volume of the ASTIN Bulletin one finds two articles (Borch 1960a, 1960b) of the man who stands for having promoted economic thought in ASTIN, Karl Borch, Professor of Economics in Bergen (Norway). Karl Borch has taught us

utility theory,

risk exchanges - with the fundamental Theorem of Borch, and he has fully exploited de Finetti's proposal.

Take the risk process as already given and introduce, as suggested by de Finetti, an upper barrier

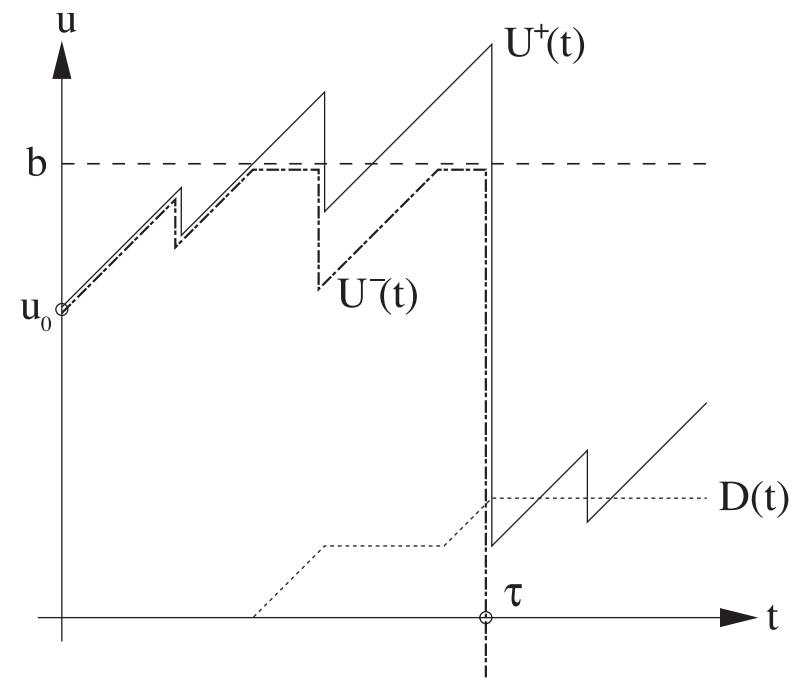

$D(t) \sim$ accumulated dividends

$U^{+}(t) \sim$ surplus with dividends

$U^{-}(t) \sim$ surplus without dividends

Introduce

$$
V\left(u_{0}, b\right)=\int_{0}^{\tau} e^{-\delta t} d D(t)
$$

Value of firm $=$ Discounted value of dividends

GOAL: Find $b^{*}$ such that $V\left(u_{0}, b^{*}\right)=\max$. 
It must be noted that by shifting paradigms

$$
\begin{array}{cl}
\begin{array}{c}
\text { from probability of ruin } \\
\text { engineer }
\end{array} & \text { to value of the firm } \\
\text { to economist }
\end{array}
$$

the behavior in the firm changes. Karl Borch noticed for example that from the economic point of view it might make sense - at least sometimes - to accept risks with a negative premium loading, which according to Karl Borch "no reasonable actuary would do." Both de Finetti and Borch also realized that maximizing the value of the firm could drive it into early ruin. To avoid this, both did suggest that the expected lifetime of the company should always be used as a control.

\section{EPILOGUE}

ASTIN today discusses a wide range of ideas. When preparing this lecture I was astonished to find how many of these ideas were - in a nutshell - present already at the time when ASTIN was founded. I think that for this fact, namely for setting the scene that could carry for fifty years and more, we should be grateful to our founding fathers. I hope that the work made within ASTIN will remain of the same type, not so much driven by short-term urgency but aimed at long-term persistence.

ASTIN is not just a section of IAA (International Actuarial Association). As we have seen, it started originally to become an Actuarial Association of its own, its style and culture being quite different from that of the mainstream actuaries. I think that our forefathers were wise to understand that the profession of the actuary could host also these newcomers under one common roof leaving them enough freedom and independence to permit a fruitful and flourishing development. Yes, ASTIN has become the trademark of new scientific inputs from mathematics and economics into the actuarial profession.

It is tempting to compare this success story of ASTIN with a further step taken by IAA in 1988. The scenario was similar. The question was: Could the new emerging techniques and paradigms of finance also be successfully hosted by the actuaries or would they rather flourish outside the actuarial profession? The solution was sought by the creation of a further IAA subsection called AFIR. The idea was that AFIR should become the think-tank of finance applied to insurance. The older sister ASTIN has successfully taken this role, when modern methods of probability theory, statistics (and to a lesser degree economics) were ready for application in insurance. I personally think that AFIR is still struggling with its task. The more should we as members of ASTIN be happy that our think-tank by its existence for fifty years has had a decisive influence on the development of the insurance sector, in particular in Non Life Insurance. 


\title{
REFERENCES
}

Ammeter, H. (1948) A Generalization of the Collective Theory of Risk in Regard to Fluctuating Basic Probabilities, Skandinarisk Aktuarik Tidshrift.

Beard, R.E., Pentikäinen, T. and Personen, E. (1969) Risk Theory, Chapman and Hall.

BorCH, K. (1960a) Reciprocal Reinsurance Treaties, ASTIN Bulletin, 1.

BorCH, K. (1960b) The Utility Concept Applied to the Theory of Insurance, ASTIN Bulletin, 1.

Cramér, H. (1930) On the Mathematical Theory of Risk, Skandia Jubilee Volume, Stockholm.

Cramér, H. (1955) Collective Risk Theory, a survey from the point of view of the theory of stochastic processes. Skandia Jubilee Volume, Stockholm.

Daykin, C.D., Pentikäinen, T. and Pesonen, M. (1994) Practical Risk Theory for Actuaries, Chapman and Hall.

DE FinetTi, B. (1957) Su unimpostazione alternativa della teoria collettiva del rischio. Transactions XV Int. Congress of Actuaries, New York.

DubeY, A. (1974) Probabilité de ruine lorsque le parametre de Poisson est ajusté a posteriori, Mitteilungen Vereinigung Schweizer Versicherungsmathematiker, 2.

Gerber, H.U. (1973) Martingales in Risk Theory, Mitteilungen Vereinigung Schweizer Versicherungsmathematiker, 2.

Gerber, H.U. (1980) An Introduction to Mathematical Risk Theory, Huebner Foundation Monograph, Wharton School, University of Pennsylvania.

HenRICI, P. (1979) Fast Fourier Methods in computational complex analysis, SIAM 21, 4.

LunDBERG, F. (1909) Zur Theorie der Rückversicherung, Berichte des Internationalen Kongresses der Versicherungsmathematiker, Wien.

Lundberg, O. (1948) On Random Processes and Their Application to Sickness and Accident Statistics, University of Stockholm Thesis, Uppsala.

PANJER, H.H. (1980) The aggregate claims distributions and Stop Loss in reinsurance, Transactions Society of Actuaries.

SEgerdahl, C.O. (1959) A Survey of Results in Collective Theory of Risk, Harald Cramér Volume, Stockholm and New York, Wiley.

Whitney, A.W. (1918) The theory of experience rating. Proc. of Cas. Act. Soc. 4.

\author{
HANS BÜHLMANN \\ ETH, Mathematik \\ CH-8092 Zürich \\ E-mail:hbuhl@math.ethz.ch
}

